\title{
Status Report of SP-100 Ground Engineering System Test Site Instrumentation, Control, and Plant Protection System Activities
}

\author{
W. F. Carlson \\ K. L. Bennett \\ G. V. Delisle \\ K. L. Hampsten \\ B. L. Philipp \\ T. C. Schneider
}

Date Published

May 1990

To be presented at 8th Symposium on Space Nuclear Power Systems Albuquerque, New Mexico January 6-10, 1991

Prepared for the U.S. Department of Energy Assistant Secretary for Nuclear Energy

(2) Westingthouse P.O. Box 1970 Pichland, Washington 99352

Hantord Operations and Engineering Contrector for the

U.S. Depertment of Energy under Contract DE-AC06-87PL10050

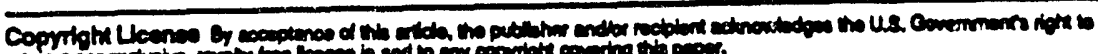

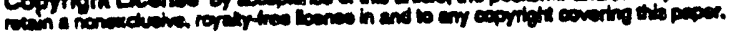




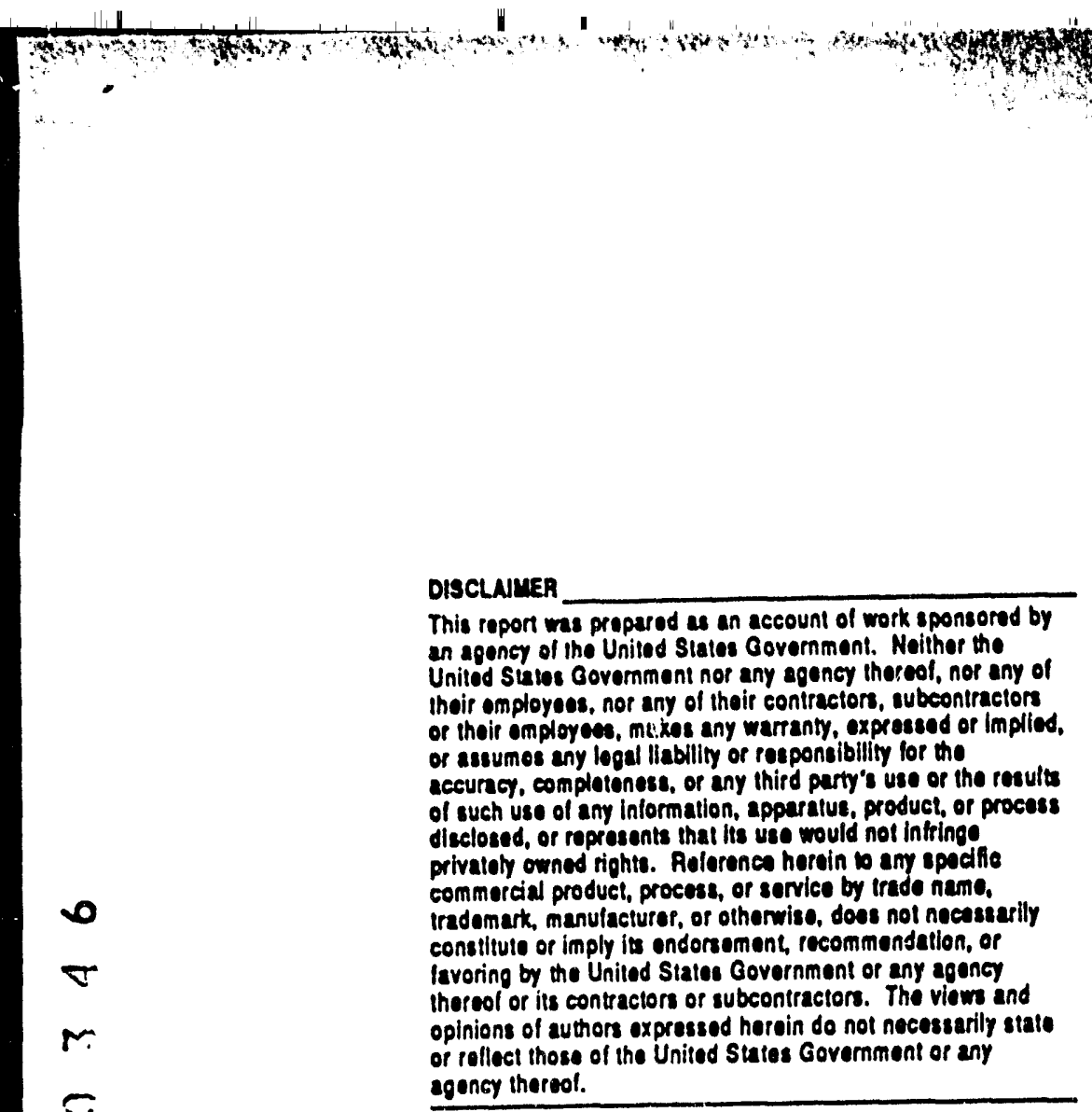

Priniw in the Unives Suber of Ameried

OISCLM-2.CHP (2+4) 


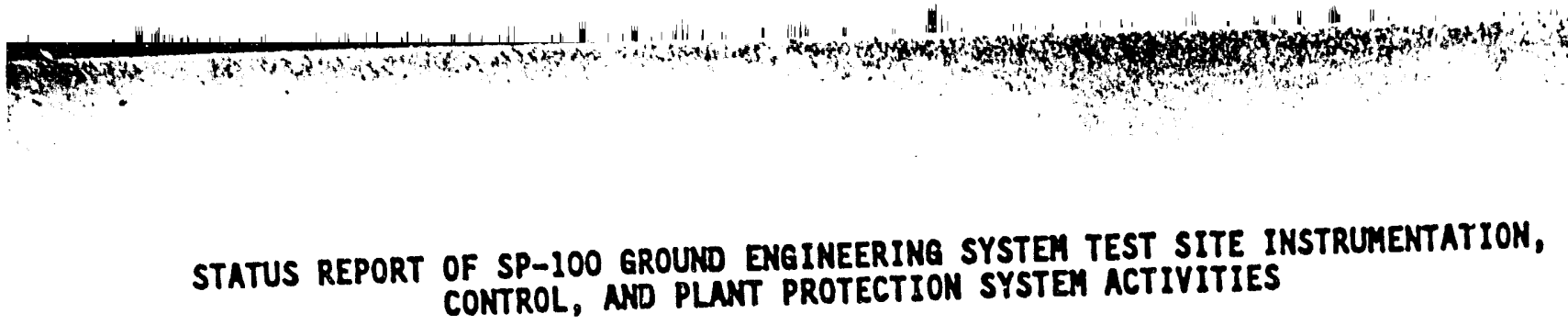

Willlam F. Carlson, Kenneth L Bennett, Gerald V. Delisle,
Kenneth L. Hampsten, Barbara L. Philipp, and Thomas C. Schneider.
Westinghouse Hanford Company
P.0. Box 1970
Richiand, WA 99352
(509) $376-7843$

\section{INTRODUCTIOH}

The facility at which the SP-100 Nuclear Assembly Tesi (NAT) of a 100-kWe The facility at which the SP-100 Nuclear Assembiy Test phase since November 1987 . Considerable progress has been made since then in the design and procurement of instrumentation and control systems.

The tests will be conducted from a central control room using modern process control technology. A microprocessor-based Distributed Control system is being provided as the means for centralized control and monitoring.

A separate, seismically hardened area, the Auxiliary Shutdown Station (AXSS), is provided from which the reactor can be safely shut down and monitored in the event that the main control room becomes uninhabitable or if the control room equipment is not functional. From the AxSS the reactor can be shut down and post accident monitoring can be conducted, as well as controlling the removal of residual heat.

The Plant Protection System includes the AXSS, a Containment Isolation System, a Reactor Protection System, and a Vacuum Vessel Purge Control System. These are all designed to automatically perform safety functions so as to protect the public from the results of accidents or natural events such as an earthquake.

A Test Data Recording and Processing (TDRP) System is also being provided which is separate from the Process Control System. This system will acquire data from both the Test Assembly and the many support systems in the Facility, and will provide the capability for complex computations and displays.

Also discussed are the Liquid Metal Trace Heating Control System and the Plant Radiation Monitoring equipment.

This paper summarizes the present status of the design and procurement activities which support these systems.

\section{EACILITY DESCRIPTION}

The SP-100 Ground Engineering System (GES) Test Site is located in Richland, Hashington. The basic functions and systems which comprise the Test Facility Hashington. The basic functions and syosium (Miller et al. 1988) and changes
have been described in a previous symposium (Me been described at the 1989
since the completion of conceptual design have sympostum (Renkey et al. 1989). Altnough the detalls of the Instrumentation and Control (I\&C) systems (such as the numbers of inputs and outputs) which 
monitor and control the Facility and Test Assembiy change as system designs evolve, the basic concepts have remained the same throughout the Conceptual, Preliminary, and Definitive Design phases.

Figure 1 is an artist's conceptual view of the Test Site showing the Containment Building in which the Test Assembly will be installed. All of the equipment to be discussed is located within the bulldings shown.

\section{SYSIEH STATUS}

System Design Specifications have been prepared for all of the I\&C and protection systems to be discussed. These project documents describe how Test Site Functions and Requirements are to be implemented, and are major design documents. Following the completion of this task, actual design was begun. Progress in each area is discussed in the following sections.

\section{Process Control System}

A purchase order was issued to Powell Process Systems of Houston, TX, in March 1989 for a Distributed Process Control System. The system incorporates state-of-the-art microprocessor technology with color graphics operator interfaces. Approximately 1,000 input/output points will be avallable and the control room will contain three operator workstations, any one of which will be capable of controlling the plant. Normally, however, the three stations will be used for operator interfacing with the reactor, balance of plant, and alarms, respectively. The Reactor Control System itself, which is part of the Test Assembly, is being provided by General Electric (GE), but will interface with the control room aisplays for operator setpoint adjustment and monitoring. This interface will be implemented using standard process analog and discrete inputs and outputs. This arrangement, rather than the use of digital data links, allows the designs and procurements of $G E$ and Westinghouse Hanford Company (Westinghouse Hanford) equipment to proceed in parailel. Figure 2 illustrates the GE/Westinghouse Hanford interfaces.

The Process Control System (PCS) is to be delivered in late 1990. It will be staged in a previously prepared area for preliminary configuration and engineering training while the control room is being constructed.

Preparation of Control and Monitoring Requirements (C\&MR) documents for each system has been initlated, with the goal of having first revisions for all systems complete in August 1990 . These C\&MRs contain information which is the basis for configuring the PCS.

\section{Plant Protection System}

The AXSS is located immediately below a portion of the control room. It is easily accessible to the operators if the control room becomes uninhabitable for any reason. It is not intended as an alternate control room, but if operations become untenable in the control room, the reactor will be shut down and the function of decay heat removal will continue using the AXSS. 


\section{Other Equitement}

A varlety of liquid metal sensors have been obtained from another profect. It appears that these will meet all presently known requirements for these types of sensors. This is a significant acquisition, because sensors for measuring liquid metal pressure are no longer manufactured in the United States.

Finally, the requirements for measurement of radiation in the Facllity have been documented and equipment sources have been identified. Some equipment has been located el sewhere on the Hanford Site and acquisition steps are being taken.

\section{SUHWARY}

Design and procurement activities in the I\&C area are proceeding on schedule in parallel with the designs of the other facility systems. This ensures that there is regular collaboration between the I\&C engineers and the other facility system designers. In addition, close cooperation between GE and Westinghouse Hanford engineers has made it possible for the Test Site to track the evolution of requirements generated by GE as the design and testing requirements of the Test Assembiy evolve.

All activities are scheduled so as to have the necessary equipment onsite in late 1992 when installation is to begin. The arrival of the PCS equipment in late 1990 represents the first of these major procurements.

\section{Acknowledgements}

This work was sponsored by the U.S. Department of Energy under Contract DE-AC06-87RL10930.

\section{References}

Miller, W. C., J. L. Etheridge, P. J. Brackenbury, W. F. Carlson, P. A. Edwards, J. J. Irwin, E. J. Renkey, and E. J. Shen, 1988, "Conceptual Design of the SP-100 GES Test Site," in Soace Nuclear Power Systems 1987, V7, M. S. El-Genk and M. D. Hoover, eds., Orbit Book Co., Malabar, Florida.

Renkey, E. J., G. D. Bazinet, E. J. Bitten, P. J. Brackenbury, W. F. Carison, J. J. Irwin, P. A. Edwards, E. J. Shen, and P. A. Titzler, 1989, site," WHC-SA-0608-A, presented at the 7th Symposium on Space Nuclear Power Systems, Albuquerque, New Mexico. 


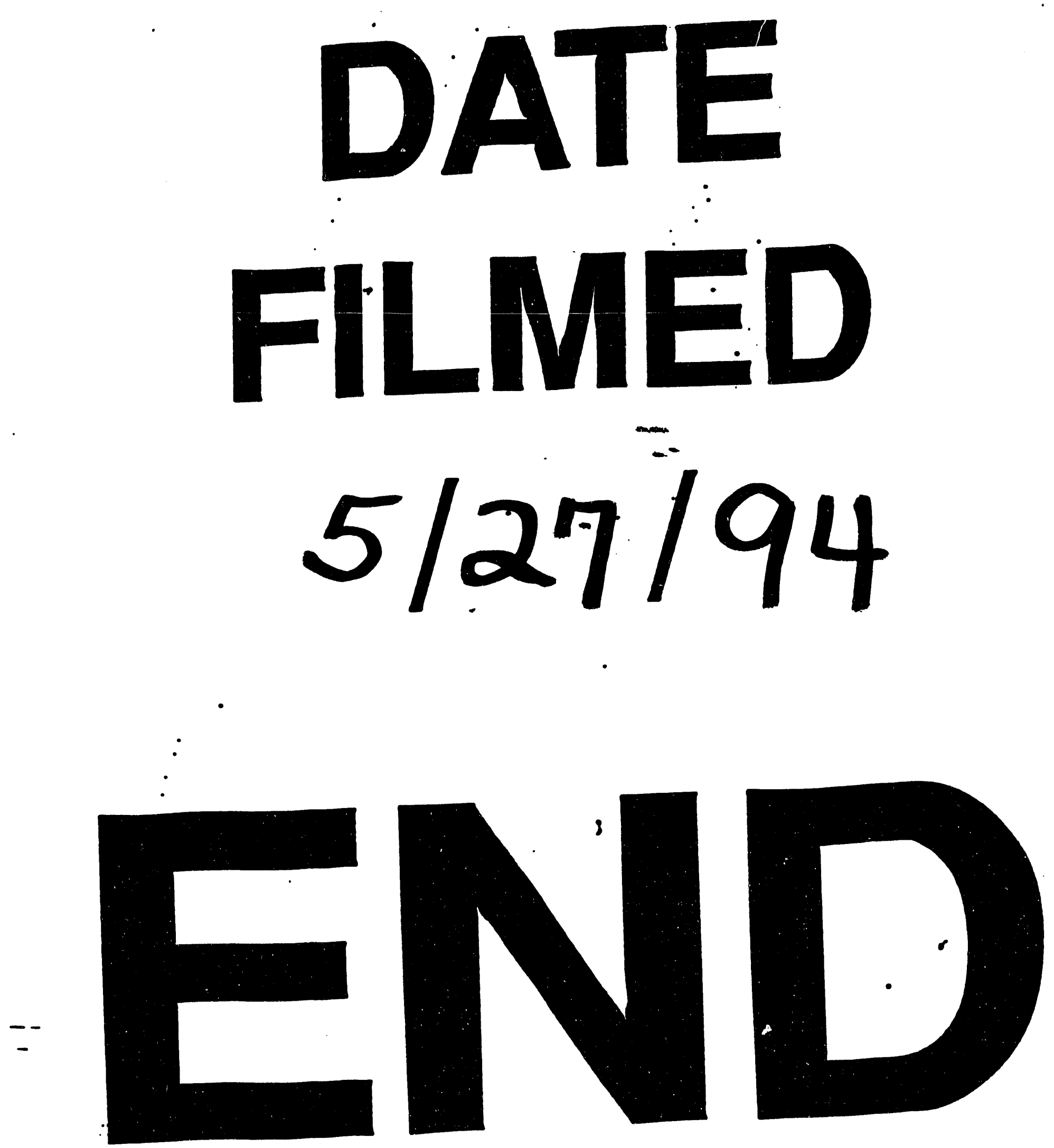


$\ldots$ .

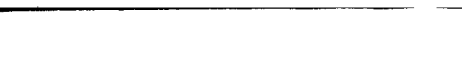
然 